\title{
Eugenol inhibits veratridine-induced non-convulsive seizures and wet dog shakes via blockage of sodium and calcium influx in rat cerebrocortical synaptosomes
}

\author{
Ransford Amoah, Priscilla Kolibea Mante*, Nana Ofori Adomako, Paulina Antwi \\ Department of Pharmacology, Kwame Nkrumah University of Science and Technology, Kumasi, Ghana.
}

\section{ARTICLE INFO \\ Received on: 01/07/2021 \\ Accepted on: 19/09/2021 \\ Available Online: 05/01/2022}

\section{Key words:}

Absence seizure, sodium

channels, calcium channels,

EEG, valproate.

\begin{abstract}
Studies have confirmed that the electroencephalogram (EEG) pattern produced by veratridine (VTD) administration is comparable to that seen in absence seizures, partial seizures, and epileptic encephalopathies. VTD has thus been considered a valuable epileptogenic agent for screening of antiepileptic agents. This study investigated the activity of eugenol (EUG) against VTD-induced seizures. Seizures were induced in Sprague-Dawley rats with VTD (400 $\mu \mathrm{g} / \mathrm{kg}$; i.p.) after implantation of electrodes for electroencephalogram recording. Animals were observed for seizure activity and the number of wet dog shakes (WDS). The number of WDS was significantly $(p=0.0141)$ reduced by pretreatment with EUG at $100 \mathrm{mg} / \mathrm{kg}$. Animals experienced frequent quiescent periods with recorded epileptiform activity. Pretreatment with $400 \mathrm{mg} / \mathrm{kg}$ ethosuximide and $200 \mathrm{mg} / \mathrm{kg}$ valproic acid abolished spike activity. Pretreatment with EUG at $100 \mathrm{mg} / \mathrm{kg}$ was more effective against inhibition of spike activity. EUG also significantly ( $p=0.0001)$ inhibited the influx of sodium and calcium ions in cerebrocortical synaptosomes from isolated rat brains. EUG inhibits VTD-induced nonconvulsive seizures and WDS in rats.
\end{abstract}

\section{INTRODUCTION}

Epilepsy is a chronic neurological condition which affects roughly 50 million people worldwide (Fiest et al., 2017). Epilepsy is a major concern for public health given its significant impact on the physical, social, cultural, and economic aspects of an individual. Research focused on understanding epileptogenesis and the development of more efficacious and safer antiepileptic drugs is thus important. The quest to identify potential, novel therapeutic agents for the management of epilepsy necessitates the use of seizure models.

Veratridine (VTD) is a nonselective activator of voltagegated sodium channels and calcium channels (Weuring et al., 2020; Zhang et al., 2017). It has been used in various in vitro and in vivo models and has shown to possess seizure-inducing

${ }^{*}$ Corresponding Author

Priscilla Kolibea Mante, Department of Pharmacology, Kwame Nkrumah University of Science and Technology, Kumasi, Ghana. E-mail: pkmante. pharm@knust.edu.gh activity in rodents, wild-type zebrafish, and hippocampal slices (Otoom et al., 2006; Singh and Goel, 2016; Weuring et al., 2020). Based on the spontaneous and rhythmic neuronal bursting activity observed in electrophysiological studies on hippocampal CA1 pyramidal neurons and in vivo rodent and zebrafish activity, studies have confirmed that the EEG pattern after VTD administration is comparable to that seen in absence seizures, partial seizures, and epileptic encephalopathies (Otoom and Sequeira, 2011; Singh and Goel, 2016; Weuring et al., 2020). VTD has been commonly applied to study drugs that act on voltagegated sodium and calcium channels (Atkin et al., 2018; Craig et al., 2020). Therapeutic concentrations of several antiepileptic drugs including valproic acid have been shown to inhibit VTDinduced seizure activity (Otoom and Alkadhi, 2000). In vivo, VTD also produces behavioral effects such as facial automatisms and masticatory jaw movement (Otoom et al., 2006). These behaviors usually culminate in the development of wet dog shakes (WDS). VTD promotes the influx of $\mathrm{Na}^{+}$and intracellular $\mathrm{Ca}^{2+}$ causing depolarization in the cells (Zhang et al., 2018) and has been applied as a tool for screening potential antiepileptic drugs. 
In the development of newer drugs, medicinal herbs have served as a rich source of lead compounds (pradhan and Panchawat, 2018). One such lead compound, eugenol (EUG), is a major constituent of numerous medicinal plants and is extracted from essential oils such as clove and cinnamon oils. It may also be obtained from other plants such as Myristica fragrans (nutmeg). EUG has been employed as a pain reliever in dental practice for several years, with scientifically established analgesic and anesthetic properties (Nejad et al., 2017). It also has been investigated for antioxidant and anticonvulsant actions (Barboza et al., 2018; Ogata et al., 2000). The possible application of EUG in the management of depression, Alzheimer's, and Parkinson's diseases has also been explored (Irie, 2006). EUG has also been proposed to have inhibitory action on voltagegated calcium and sodium, as well as potassium, channels (Chung et al., 2008; Nisar et al., 2021) and anticonvulsant activity against electrical and chemical-induced seizures in pilocarpine and nicotine models (Joushi and Salmani, 2017; Karampour et al., 2017; Yadav et al., 2018).

We, therefore, hypothesize that EUG's blockade of calcium and sodium currents and anticonvulsant effects in other epilepsy models would make it useful against seizures mediated by VTD's action on calcium and sodium channels. EUG's activity against VTD-induced seizures was, therefore, explored in this study.

\section{METHODS}

\section{Chemicals}

VTD (400 $\mu \mathrm{g} / \mathrm{kg}$ ), ethosuximide (ETX, $400 \mathrm{mg} / \mathrm{kg}$ ), sodium valproate (VPA, $200 \mathrm{mg} / \mathrm{kg}$ ), and EUG (30 and $100 \mathrm{mg} / \mathrm{kg}$ ) were purchased from Sigma-Aldrich, USA, and dissolved in 1\% ethanol. VTD, ETX, and VPA were administered intraperitoneally, while EUG was administered orally. All intraperitoneal drug treatments were administered 30 minutes before administration of VTD, and oral administration was carried out 1 hour before VTD. All drug treatments were carried out by acute administration. The dosing for EUG, VTD, ETX, and VPA was based on previous studies (Barot and Saxena, 2021; Dal Bó et al., 2013; Ramazi et al., 2020).

\section{EEG and WDS recordings}

Male Sprague-Dawley rats $(250-280 \mathrm{~g} ; n=7)$ were obtained from the Departmental Animal Facility. Animals received anesthesia using chloral hydrate $(500 \mathrm{mg} / \mathrm{kg}$; i.p. $)$ and buprenorphine $(0.1 \mathrm{mg} / \mathrm{kg}$; i.p. $)$, after which they were placed in a stereotaxic frame. Three polyamide-insulated stainless steel electrodes ( $\mathrm{p} 1$ Technologies, Roanoke, VA) were constructed and implanted as described by Jeffrey et al. (2014). Anesthesia was discontinued after implantation, and animals were given 7 days for full recovery. A flexible connector cable was then attached to the electrode pedestal and attached to an amplifier (eight-channel) and an analog-digital converter (AD Instruments Ltd., East Sussex, UK). Signals were recorded along a frequency bandwidth of $0.1-$ $1000 \mathrm{~Hz}$. Chart4 software for Windows (AD Instruments Ltd., East Sussex, UK) was used for data recording and analyses for a 60-minute period. Onset time and number of WDS were recorded after VTD administration for a 30-minute period. Animals were also videotaped.
Ethical clearance for the study was given by the Animal Ethics Committee, Kwame Nkrumah University of Science and Technology (KNUST), and experiments were conducted in accordance with the Guiding Principles for the Care and Use of Laboratory Animals.

Sample size was determined using a power analysis with the G*Power software (Heinrich-Heine-Universität Düsseldorf). No explicit criteria were set for the inclusion or exclusion of animals in the groups. Animals were randomly allocated to groups, and treatments were blinded.

\section{Preparation of brain samples}

After the experiment, the rats were sacrificed via cervical dislocation and brain tissue samples excised. The cerebral cortex was dissected and synaptosomes were prepared as previously described by Nicholls and Sihra (1986). Synaptosomal pellets were resuspended in an 4-(2-hydroxyethyl)-1-piperazineethanesulfonic acid (HEPES) buffer medium (HBM) containing (in mM) HEPES, $10 ; \mathrm{KCl}, 5 ; \mathrm{NaCl}, 140 ; \mathrm{MgCl}_{2} 6 \mathrm{H}_{2} \mathrm{O}, 1 ; \mathrm{NaHCO}_{3}, 5 ; \mathrm{Na}_{2} \mathrm{HPO}_{4}, 1.2$; and glucose, 10; $\mathrm{pH}$ was 7.4. The Bradford assay was then used to determine protein concentration. Synaptosomal pellets $(0.5 \mathrm{mg}$ protein) were obtained and stored on ice for further analysis.

\section{Intrasynaptosomal calcium concentration $\left(\left[\mathrm{Ca}^{2+}\right]_{\mathrm{i}}\right)$}

Synaptosomes $(2 \mathrm{mg} / \mathrm{ml})$ were resuspended in the HBM containing Bovine Serum Albumin (BSA) $(16 \mu \mathrm{M})$ in the presence of fura-2 $(5 \mu \mathrm{M})$ and $\mathrm{CaCl}_{2}(0.1 \mathrm{mM})$ and incubated for 30 minutes at $37^{\circ} \mathrm{C}$. Fura-2 was loaded and pelleted synaptosomes were resuspended in the HBM with BSA. A $1 \mathrm{ml}$ aliquot was stirred in $\mathrm{CaCl}_{2}(1.2 \mathrm{mM})$, and fluorescence was measured at excitation wavelengths of 340 and $380 \mathrm{~nm}$ (with a $505 \mathrm{~nm}$ emission wavelength). Data were recorded at 2-second intervals, and $\left[\mathrm{Ca}^{2+}\right]$ (nM) was computed as described previously by Grynkiewicz et al. (1985).

\section{Intrasynaptosomal sodium concentration $\left(\left[\mathrm{Na}^{+}\right]_{\mathrm{i}}\right)$}

$\left[\mathrm{Na}^{+}\right]_{\mathrm{I}}$ measurements were carried out as described by Cao et al. (2008). Synaptosomes were incubated with a dyeloading buffer $(100 \mu \mathrm{l} /$ well) containing $10 \mu \mathrm{M}$ (SBFI-AM) Sodium-binding Benzofuran Isophthalate (Invitrogen) and $0.02 \%$ Pluronic F-127 (Invitrogen) at $37^{\circ} \mathrm{C}$ for 1 hours. Sodium-bound SBFI emission was measured at $505 \mathrm{~nm}$ (excitation wavelengths: 340 and $380 \mathrm{~nm}$ ). Fluorescence data were recorded at 5-second intervals, and $[\mathrm{Na}+]_{\mathrm{i}}(\mathrm{nM})$ was computed using equations described previously by Jabba et al. (2010).

\section{Data analysis}

Data were analyzed for statistical differences by oneway analysis of variance (ANOVA), followed by Tukey's posthoc test with GraphPad Prism software v 8.0 (San Diego, CA). $p \leq$ 0.05 was considered statistically significant. Data from all animals were included during data analysis.

\section{RESULTS}

WDS

Intraperitoneal VTD at concentrations of $400 \mu \mathrm{g} / \mathrm{kg}$ produced facial automatisms and WDS within $22.29 \pm 2.254$ 
A

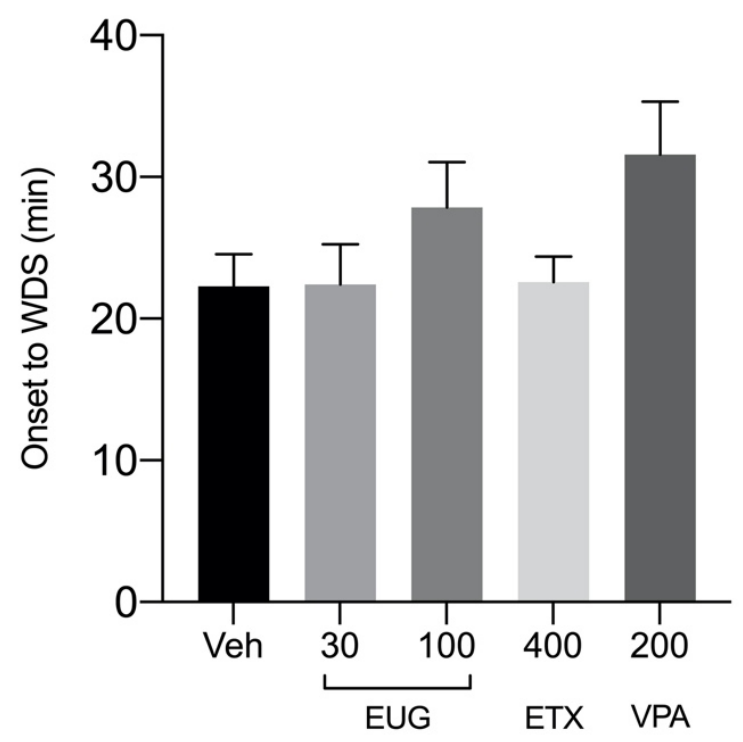

B

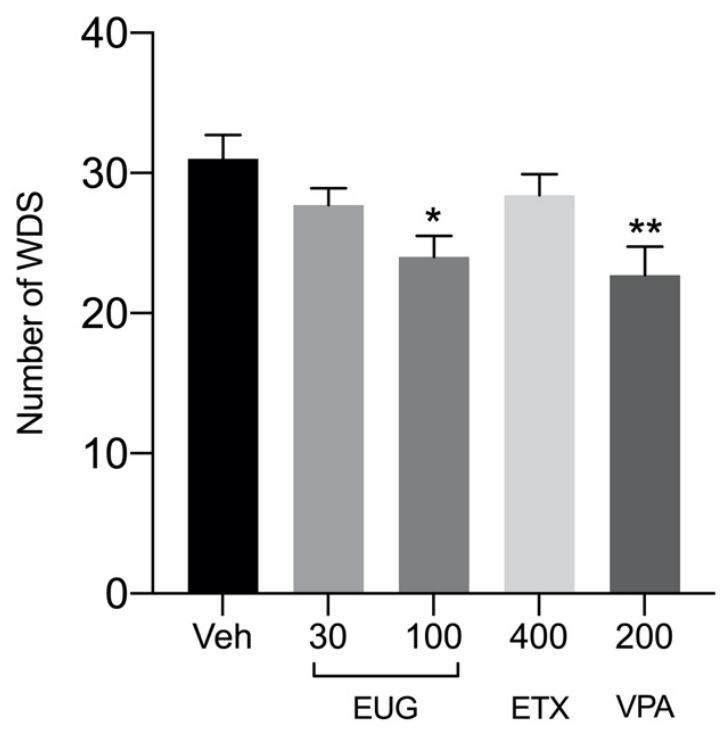

C

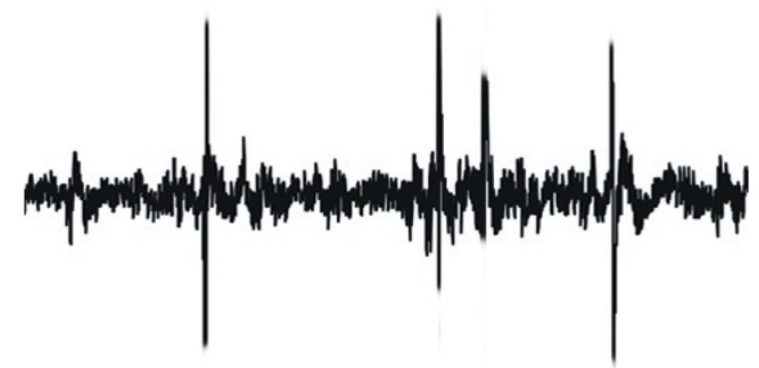

Figure 1. Onset to WDS (A) and number of WDS (B) induced by intraperitoneal administration of VTD ( $400 \mu \mathrm{g} / \mathrm{kg})$ after pretreatment with EUG 30 and $100 \mathrm{mg} / \mathrm{kg}$, p.o., ETX (400 mg/kg; i.p.), and VPA (200 mg/kg; i.p.). (C) Representative EEG spike activity for WDS. Significant differences in comparison with the vehicle-treated group, ${ }^{*} p \leq 0.05 ; * * \leq 0.001$ (one-way ANOVA, followed by Tukey's test), $n=7$.

minutes. WDS were associated with spike activity on the EEG in some animals (Fig. 1C). The number of WDS was significantly reduced by pretreatment with EUG at $100 \mathrm{mg} / \mathrm{kg}$ [Fig. 1B, $p=$ $0.0141 ; F(2,18)=5.453]$ and VPA [Fig. 1B, $p=0.0081 ; F$ $(2,18)=6.368]$. All pretreatments did not significantly alter onset times of WDS.

\section{EEG recordings}

Animals experienced frequent quiescent periods which lasted between 1 and 5 minutes, after which they resumed regular activity. The quiescent periods were recurrent every 12-25 minutes. Epileptiform activity was recorded on the EEG during the quiescent periods. Figure $2 \mathrm{C}$ shows the seizure activity recorded during quiescent periods in VTD-only-treated rats. In animals pretreated with $200 \mathrm{mg} / \mathrm{kg}$ ETX (Fig. 2E) and VPA (Fig. 2F), EEG recording did not display the fast frequency spike activity, similar to vehicle-treated animals (Fig. 2A). Pretreatment with EUG at
$100 \mathrm{mg} / \mathrm{kg}$ was more effective against inhibition of spike activity (Fig. 2D). No deaths were recorded.

\section{Intrasynaptosomal calcium $\left(\left[\mathrm{Ca}^{2+}\right]_{i}\right)$ and sodium concentrations $\left(\left[\mathrm{Na}^{+}\right]_{\mathrm{i}}\right)$}

Table 1 shows the effects of pretreatments of EUG, ETX, and VPA on synaptosomal $[\mathrm{Ca} 2+]_{i}$ and $[\mathrm{Na}+]_{i}$ concentrations. VTD treatment caused a significant $[p=0.0001 ; F(5,36)=35.72]$ rise in both $\left[\mathrm{Ca}^{2+}\right]_{\mathrm{i}}$ and $\left[\mathrm{Na}^{+}\right]_{\mathrm{i}}$ concentrations to a plateau level. Rats pretreated with EUG $100 \mathrm{mg} / \mathrm{kg}$ had significantly lower synaptosomal $\left[\mathrm{Ca}^{2+}\right]_{\mathrm{i}}[p=0.0001 ; F(4,30)=127.2]$ and $\left[\mathrm{Na}^{+}\right]_{i}$ $[p=0.0001 ; F(3,24)=30.26]$ concentrations compared to VTDonly rats. ETX $400 \mathrm{mg} / \mathrm{kg}$ significantly prevented a rise in $\left[\mathrm{Ca}^{2+}\right]_{i}$ $[p=0.0001 ; F(2,18)=214.7]$ but failed to prevent a rise in $\left[\mathrm{Na}^{+}\right]_{\mathrm{i}}$. VPA significantly $(p=0.0001)$ inhibited a rise in both $\left[\mathrm{Ca}^{2+}\right]_{\mathrm{i}}$ and $\left[\mathrm{Na}^{+}\right]_{\mathrm{i}}$ concentrations. 
A
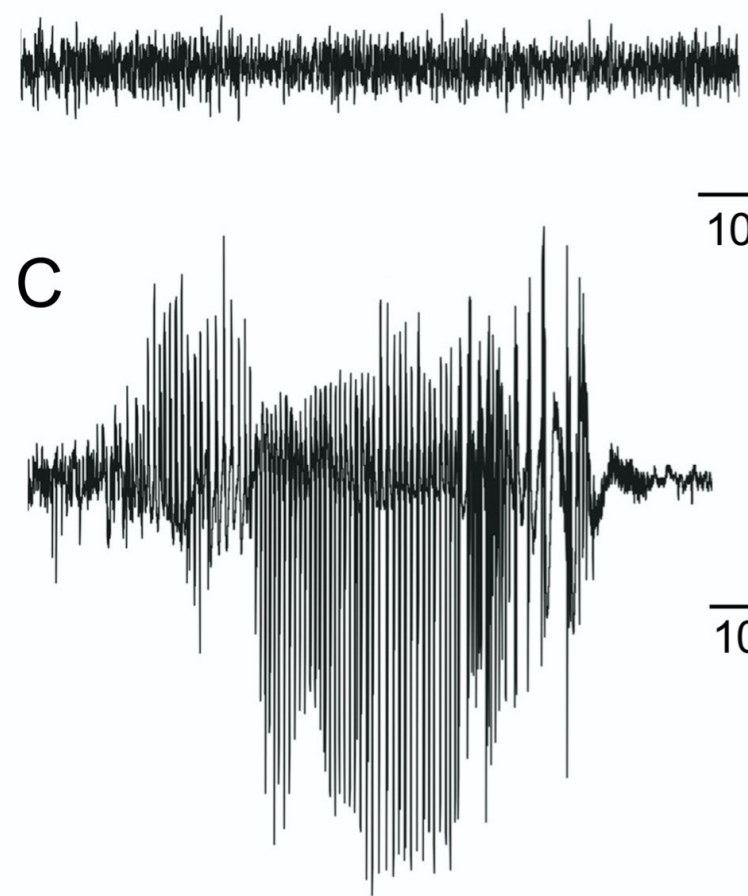

\section{B}

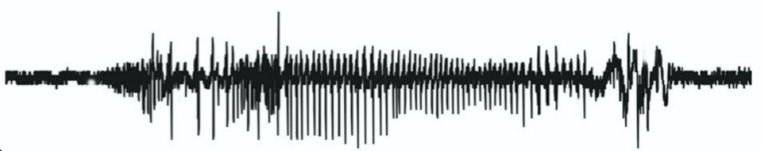

$0.1 \mathrm{mV}$

$10 \mathrm{~s}$

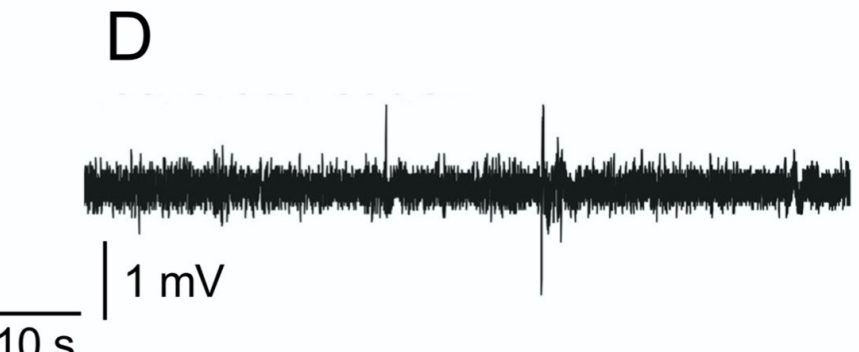

$10 \mathrm{~s}$

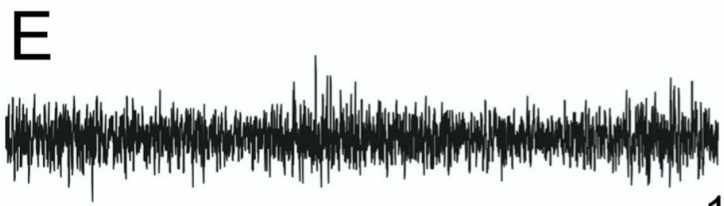

$\mathrm{F}$

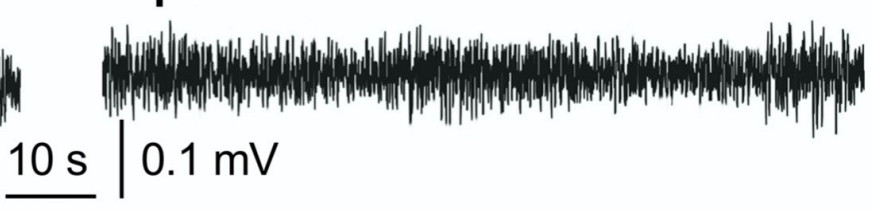

Figure 2. EEG recordings from (A) vehicle-treated control rats, (B) $30 \mathrm{mg} / \mathrm{kg}$ EUG-pretreated rats, (C) VTD-only-treated rats, (D) $100 \mathrm{mg} / \mathrm{kg}$ EUGpretreated rats, (E) ETX-pretreated rats, and (F) VPA-pretreated rats. VTD-only-treated rats presented fast frequency spike activity.

Table 1. Effect of EUG, ETX, and VPA on $\mathrm{Ca}^{2+}$ and $\mathrm{Na}^{+}$in rat cerebrocortical synaptosomes.

\begin{tabular}{cccc}
\hline & {$\left[\mathbf{C a}^{2+}\right]_{i}(\mathbf{n M})$} & {$\left[\mathbf{N a}^{+}\right]_{i}(\mathbf{n M})$} & $\boldsymbol{n}$ \\
\hline Vehicle & $90.45 \pm 8.53$ & $18.55 \pm 1.6$ & 7 \\
VTD-only & $232.7 \pm 3.11^{* * *}$ & $34.1 \pm 0.89^{* * *}$ & 7 \\
EUG $30 \mathrm{mg} / \mathrm{kg}$ & $221.34 \pm 6.05$ & $32.86 \pm 2.45$ & 7 \\
EUG $100 \mathrm{mg} / \mathrm{kg}$ & $143.12 \pm 4.67^{*}$ & $19.34 \pm 0.03^{*}$ & 7 \\
ETX 400 mg/kg & $106.61 \pm 1.52^{*}$ & $28.56 \pm 1.23$ & 7 \\
VPA 200 mg/kg & $134.81 \pm 1.90^{*}$ & $11.59 \pm 1.67^{*}$ & 7 \\
\hline
\end{tabular}

Significant differences in comparison with the vehicle-treated group $* * * p \leq$ $0.001,{ }^{*} p \leq 0.001$ significant differences in comparison with the VTD-only group (one-way ANOVA, followed by Tukey's test), $n=7$.

\section{DISCUSSION}

The EEG pattern after VTD administration has been previously confirmed to be comparable to that seen in absence seizures. This has been further supported by the ability of ETX to control VTD-induced seizures (Otoom and Sequeira, 2011). The use of VTD is, therefore, considered a useful animal seizure model for screening antiepileptics, particularly those likely to be effective against absence seizures (Otoom and Sequeira, 2011). Previous findings have also indicated that VTD produces behavioral effects similar to kainic acid-induced effects; kainic acid administration is considered to model complex partial seizures similar to temporal lobe epilepsy in humans. Kainic acid-induced seizures in rodents result in characteristic facial automatisms such as head bobbing and, ultimately, WDS (Lévesque and Avoli, 2013).

In our study, animals receiving VTD exhibited quiescent behaviors with attendant epileptiform activity somewhat similar to that which occurs in absence seizures. In addition, the rats exhibited WDS after about 20 minutes of VTD-only administration. In vivo studies on behavioral effects of VTD show that it produces WDS accompanied by neuronal apoptosis in the hippocampus in a dose-dependent manner (Otoom et al., 2006). Animals exhibiting this behavior experience shakes of the head and the trunk. This behavior has been observed in other partial epilepsy models such as limbic kindling stimulation (Kleinrok and Turski, 1980). Interestingly, the involvement of limbic structures in absence seizures has also been explored (Chan et al., 2004). 
The limbic circuitry has been shown to be involved in both clinical and experimental atypical absence seizures. Both clinical and experimental atypical absence seizures are commonly associated with severe cognitive impairment, in which the involvement of the thalamohippocampal circuitry has been shown (Chan et al., 2004). Observations of both absence seizure-like effects and WDS in this study may, therefore, be due to an interplay of different brain circuitries (Chan et al., 2004).

Many studies have shown that WDS in rats are mediated by $5-\mathrm{HT}_{2}$ receptors (Garabadu et al., 2015). The antiepileptic effect of EUG observed as a reduction in the frequency of WDS may, therefore, be associated with interactions with the 5-HT system. Moreover, EUG has been previously reported to reverse and normalize alterations in the serotoninergic system (Garabadu et al., 2015). In this study, EUG may thus be acting by inhibiting the actions of 5-HT that was released due to VTD administration. VTD has previously been shown to increase 5-HT release in the brainstem (Bortolozzi and Artigas, 2003).

Additionally, EUG inhibited epileptiform activity induced with VTD as observed in the EEG. Seizure activity induced by VTD in vivo may be mediated in part by the activity of voltagegated calcium channels. Other channels such as voltage-gated $\mathrm{Na}^{+}$channels may be involved; VTD shifts the activation of these channels to negative membrane potentials and delays inactivation (Dorandeu et al., 2017). We, therefore, hypothesize that the efficacy of EUG in reducing absence-like seizures, demonstrated in this study by the inhibition of spike activity, may be related to interaction with voltage-gated calcium channels and/or sodium channels. T-type calcium channels especially have been associated with the pathophysiology of absence seizures. Medications such as ETX and VPA that suppress T-type calcium channels have been shown to be effective in the management of absence seizures (Albuja and Murphy, 2018). Similar efficacies have been observed in this study. Furthermore, EUG's calcium-modulating activity was confirmed by its ability to inhibit a rise in cytosolic calcium in rat brain synaptosomes in this study. EUG's efficacy against VTD-induced seizures may, therefore, be additionally due to the attenuation of a rise in cytosolic sodium in rat brains. This further confirms previous reports on EUG's activity against calcium and sodium ionic influx and currents (Irie, 2006).

\section{CONCLUSION}

In conclusion, EUG may, therefore, potentially be used in the management of both complex partial seizures and absence seizures or as an adjunct in the management of these conditions. However, further research is required to ascertain the exact mechanism of EUG in the amelioration of seizures.

\section{DATA AVAILABILITY}

All data will be provided on request from the corresponding author.

\section{AUTHOR CONTRIBUTIONS}

All authors made substantial contributions to conception and design, acquisition of data, or analysis and interpretation of data; took part in drafting the article or revising it critically for important intellectual content; agreed to submit to the current journal; gave final approval of the version to be published; and agree to be accountable for all aspects of the work. All the authors are eligible to be an author as per the international committee of medical journal editors (ICMJE) requirements/guidelines.

\section{FUNDING}

There is no funding to report.

\section{CONFLICTS OF INTEREST}

The authors report no financial or any other conflicts of interest in this work.

\section{PUBLISHER'S NOTE}

This journal remains neutral with regard to jurisdictional claims in published institutional affiliation.

\section{REFERENCES}

Albuja AC, Murphy PB. Absence seizure. StatPearls Publishing, Treasure Island, FL, 2018.

Atkin TA, Maher CM, Gerlach AC, Gay BC, Antonio BM, Santos SC, Padilla KM, Rader J, Krafte DS, Fox MA, Stewart GR. A comprehensive approach to identifying repurposed drugs to treat SCN 8A epilepsy. Epilepsia, 2018; 59(4):802-13.

Barboza JN, da Silva Maia Bezerra Filho C, Silva RO, Medeiros JV, de Sousa DP. An overview on the anti-inflammatory potential and antioxidant profile of eugenol. Oxid Med Cell Longev, $2018 ; 2018$

Barot J, Saxena B. Therapeutic effects of eugenol in a rat model of traumatic brain injury: a behavioral, biochemical, and histological study. J Traditi Complement Med, 2021; 11(4):318-27.

Bortolozzi A, Artigas F. Control of 5-hydroxytryptamine release in the dorsal raphe nucleus by the noradrenergic system in rat brain Role of $\alpha$-adrenoceptors. Neuropsychopharmacology, 2003; 28:421-34; doi:10.1038/sj.npp.1300061

Cao Z, George J, Gerwick WH, Baden DG, Rainier JD, Murray $\mathrm{TF}$. Influence of lipid-soluble gating modifier toxins on sodium influx in neocortical neurons. J Pharmacol Exp Ther, 2008; 326:604-13.

Chan KF, Jia Z, Murphy PA, Burnham WM, Cortez MA, Snead III OC. Learning and memory impairment in rats with chronic atypical absence seizures. Exp Neurol, 2004; 190:328-36.

Chung G, Rhee J, Jung S, Kim J, Oh S. Modulation of CaV2. 3 calcium channel currents by eugenol. J Dent Res, 2008; 87:137-41.

Craig RA, Garrison CE, Nguyen PT, Yarov-Yarovoy V, Du Bois J. Veratridine: a janus-faced modulator of voltage-hated sodium ion channels. ACS Chem Neurosci, 2020; 11(3):418-26.

Dal Bó W, Luiz AP, Martins DF, Mazzardo-Martins L, Santos AR. Eugenol reduces acute pain in mice by modulating the glutamatergic and tumor necrosis factor alpha (TNF- $\alpha$ ) pathways. Fundam Clin Pharmacol, 2013; 27(5):517-25.

Dorandeu F, Calas G, Dal Bo G, Fares R. 2017. Chapter 36-Models of chemically-induced acute seizures and epilepsy: toxic compounds and drugs of addiction, in models of seizures and epilepsy. 2nd edition. In: Pitkänen A, Buckmaster PS, Galanopoulou AS, Moshé SL (eds.). Models of seizures and epilepsy, Academic Press, Cambridge, MA, pp 529-51.

Fiest KM, Sauro KM, Wiebe S, Patten SB, Kwon CS, Dykeman J, Pringsheim T, Lorenzetti DL, Jetté N. Prevalence and incidence of epilepsy: a systematic review and meta-analysis of international studies. Neurology, 2017; 88(3):296-303.

Garabadu D, Shah A, Singh S, Krishnamurthy S. Protective effect of eugenol against restraint stress-induced gastrointestinal dysfunction: potential use in irritable bowel syndrome. Pharm Biol, 2015; 53:968-74.

Grynkiewicz G, Poenie M, Tsien RY. A new generation of Ca2+ indicators with greatly improved fluorescence properties. J Biol Chem, $1985 ; 260: 3440-50$. 
Irie Y. Effects of eugenol on the central nervous system: its possible application to treatment of alzheimer's disease, depression, and parkinson's disease. Current Bioact Compd, 2006; 2:57-66.

Jabba SV, Prakash A, Dravid SM, Gerwick WH, Murray TF. Antillatoxin, a novel lipopeptide, enhances neurite outgrowth in immature cerebrocortical neurons through activation of voltage-gated sodium channels. J Pharmacol Exp Ther, 2010; 332:698-709.

Jeffrey M, Lang M, Gane J, Chow E, Wu C, Zhang L. Novel anticonvulsive effects of progesterone in a mouse model of hippocampal electrical kindling. Neuroscience, 2014; 257:65-75.

Joushi S, Salmani ME. Effect of eugenol on lithium-pilocarpine model of epilepsy: behavioral, histological, and molecular changes. Iran J Basic Med Sci, 2017; 20(7):745.

Karampour NS, Arzi A, Namazifar S. Eugenol efficacy in preventing nicotine-induced seizures in mice. Natl J Physiol Pharm Pharmacol, 2017; 7(11):1C-5.

Kleinrok Z, Turski L. Kainic acid-induced wet dog shakes in rats. Naunyn Schmiedeberg Arch Pharmacol, 1980; 314:37-46.

Lévesque M, Avoli M. The kainic acid model of temporal lobe epilepsy. Neurosci Biobehav Rev, 2013; 37:2887-99.

Nejad SM, Özgüneş H, Başaran N. Pharmacological and toxicological properties of eugenol. Turkish J Pharm Sci, 2017; 14(2):201.

Nicholls DG, Sihra TS. Synaptosomes possess an exocytotic pool of glutamate. Nature, 1986; 321:772-3.

Nisar MF, Khadim M, Rafiq M, Chen J, Yang Y, Wan CC Pharmacological properties and health benefits of eugenol: a comprehensive review. Oxid Med Cell Longev, 2021; 2021.

Ogata M, Hoshi M, Urano S, Endo T. Antioxidant activity of eugenol and related monomeric and dimeric compounds. Chem Pharm Bull, 2000; 48:1467-9.

Otoom S, Sequeira RP. Veratridine induced absence like-seizure in the freely moving rats: a study correlating the behavioural findings with the electrophysiological activities. Neuroendocrinol Lett, 2011; 32:487-90.

Otoom SA, Alkadhi KA. Epileptiform activity of veratridine model in rat brain slices: effects of antiepileptic drugs. Epilepsy Res, 2000; $38: 161-70$.

Otoom SA, Handu SS, Wazir JF, James H, Sharma PR, Hasan ZA, Sequeira RP. Veratridine-induced wet dog shake behaviour and apoptosis in rat hippocampus. Basic Clin Pharmacol Toxicol, 2006; 98:423-6.
Pradhan J, Panchawat S. Herbal Therapies for epilepsy: chemistry, biology and potential applications of selected plants and compounds. Chem Biol Interface, 2018; 8(4):205-24.

Ramazi S, Fahanik-Babaei J, Mohamadi-Zarch SM, Tashakori-Miyanroudi M, Nourabadi D, Nazari-Serenjeh M, Roghani M, Baluchnejadmojarad T. Neuroprotective and anticonvulsant effects of sinomenine in kainate rat model of temporal lobe epilepsy: involvement of oxidative stress, inflammation and pyroptosis. J Chem Neuroanat, 2020; $108: 101800$

Singh D, Goel RK. Anticonvulsant mechanism of saponins fraction from adventitious roots of Ficus religiosa: possible modulation of GABAergic, calcium and sodium channel functions. Revista Brasileira de Farmacognosia, 2016,26:579-85.

Weuring WJ, Singh S, Volkers L, Rook MB, van 't Slot RH, Bosma M, Inserra M, Vetter I, Verhoeven-Duif NM, Braun KP, Rivara M. NaV1. 1 and NaV1. 6 selective compounds reduce the behavior phenotype and epileptiform activity in a novel zebrafish model for Dravet Syndrome. PloS One, 2020; 15(3):e0219106.

Yadav D, Yadav SK, Jain G, Mazumder A, Khar RK. Protective effect of eugenol against electrical induced seizure model of epilepsy. Pharm Innov J, 2018.

Zhang C, Chen J, Zhao F, Chen R, Yu D, Cao Z. Iritectol G, a novel iridal-type triterpenoid from Iris tectorum displays anti-epileptic activity in vitro through inhibition of sodium channels. Fitoterapia 2017;122:20-5.

Zhang XY, Bi RY, Zhang P, Gan YH. Veratridine modifies the gating of human voltage-gated sodium channel Nav1. 7. Acta Pharmacol Sin, 2018; 39:1716-24.

\section{How to cite this article:}

Amoah R, Mante PK, Adomako NO, Antwi P. Eugenol inhibits veratridine-induced non-convulsive seizures and wet dog shakes via blockage of sodium and calcium influx in rat cerebrocortical synaptosomes. J Appl Pharm Sci, 2022; 12(01):176-181. 